\title{
Erosividade, padrões hidrológicos e período de retorno das chuvas erosivas de Santa Rosa (RS)
}

\author{
Juliana Mazurana ${ }^{1}$, Elemar A. Cassol ${ }^{2}$, Luciana C. dos Santos ${ }^{3}$, Flávio L. F. Eltz ${ }^{4}$ \& Aristides C. Bueno ${ }^{5}$
}

\begin{abstract}
RESUMO
Este trabalho tem, como objetivo principal, determinar a erosividade, padrões hidrológicos, período de retorno e probabilidade de ocorrência das chuvas erosivas de Santa Rosa, RS, com base no período de 1975 a 2003. Foram anotados, para cada chuva considerada erosiva, a hora e a quantidade acumulada e os dados processados pelo programa computacional Chuveros, o qual calcula o índice $\mathrm{E}_{30}$ e os totais mensais e anuais da precipitação, além de determinar os padrões hidrológicos das chuvas. 0 período de outubro a março concentrou $60 \%$ da erosividade anual. 0 maior pico no potencial erosivo ocorreu em fevereiro (1.345 MJ mm ha-1 $\mathrm{h}^{-1}$ ), enquanto julho e agosto foram os meses com menor potencial erosivo (525-550 MJ mm ha-1 $\mathrm{h}^{-1}$ ). Na média, os padrões avançado, intermediário e atrasado têm 52,24 e 24\% do número de chuvas erosivas do ano, mas perfazem 58,23 e 19\%, respectivamente, do volume médio anual e 62,21 e 17\% da erosividade média anual. Espera-se que o valor da erosividade média anual que representa o fator "R" da USLE, para Santa Rosa, RS (11.217 MJ mm ha-1 $\mathrm{h}^{-1}$ ano-1) ocorra pelo menos uma vez a cada 2,3 anos, com probabilidade de ocorrência de $43,3 \%$.
\end{abstract}

Palavras-chave: energia cinética, potencial erosivo da chuva, intensidade da chuva, Fator "R", USLE

\section{Erosivity, hydrological patterns and return period of erosive rainfalls at Santa Rosa, RS - Brazil}

\begin{abstract}
The objective of this work was to determine the rainfall erosivity, hydrological patterns, return period and probability of occurrence of erosive rainfalls in Santa Rosa in the State of Rio Grande do Sul, Brazil, based on the period from 1975 to 2003. For each erosive rainfall, the time was registered along with the accumulated amount and the data processed by the software CHUVEROS, which calculates the $\mathrm{El}_{30}$ index and the monthly and annual precipitation, as well as determining the hydrological pattern of each rainfall. The period from October to March concentrates $60 \%$ of annual erosivity. The highest peak in the erosive potential occurs in February $\left(1,345 \mathrm{MJ} \mathrm{mm} \mathrm{ha-1} \mathrm{h}^{-1}\right)$, while July and August are the months of smaller erosive potential (525 - $\left.550 \mathrm{MJ} \mathrm{mm} \mathrm{ha-1}^{-1} \mathrm{~h}^{-1}\right)$. On average, the advanced, intermediary and delayed patterns have 52,24 e $24 \%$ of the number of erosive rainfalls per year, while these patterns correspond to 58,23 and $19 \%$, respectively, of the annual volume of erosive rainfalls and 62,21 and $17 \%$ of the average annual erosivity. The mean annual index of erosivity which represents the " $R$ " factor of USLE for Santa Rosa, RS, was 11,217 MJ mm ha-1 $\mathrm{h}^{-1}$ year-1, which is expected to occur once every 2.3 years, with a probability of $43.3 \%$.
\end{abstract}

Key words: kinetic energy, rainfall erosive potential, rainfall intensity, R factor, USLE

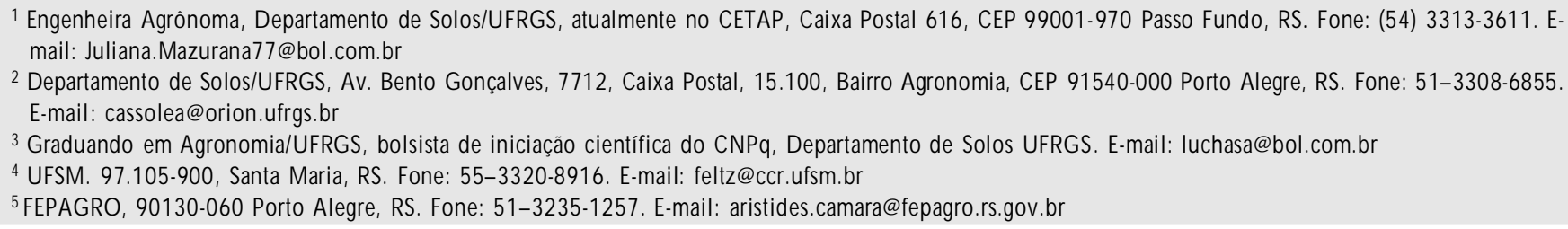




\section{INTRODUÇÃO}

Erosividade é a capacidade potencial das chuvas em causar erosão do solo, e se constitui em grande problema nas áreas de utilização agrícola dos solos. Perdas de solo por erosão hídrica podem ser estimadas pela aplicação de modelos de predição de erosão, sendo a Equação Universal de Perdas de Solo (USLE) (Wischmeier \& Smith, 1978) um dos modelos mais utilizados no mundo. Para determinação do Fator "R" da USLE, que representa a erosividade da chuva e do escoamento superficial associado, períodos de chuvas de 20 a 30 anos devem ser analisados (Wischmeier, 1976; Wischmeier \& Smith, 1978), sendo a erosividade determinada pelo índice $\mathrm{EI}_{30}$ de cada chuva. Este índice representa o produto da energia cinética total da chuva $\left(\mathrm{E}, \mathrm{MJ} \mathrm{ha}^{-1}\right)$ pela intensidade máxima da chuva com base em um período de 30 minutos contínuo de chuva $\left(\mathrm{I}_{30}, \mathrm{~mm} \mathrm{~h}^{-1}\right)$. Morais et al. (1988), baseados em correlações entre índices de erosividade da chuva e perdas de solo por erosão, concluíram que o índice de erosividade $\mathrm{EI}_{30}$ é adequado para estimar o potencial erosivo das chuvas para o Rio Grande do Sul; esta mesma conclusão foi obtida por outros pesquisadores em diferentes regiões edafoclimáticas brasileiras (Albuquerque et al., 1998; Marques et al., 1997; Lombardi Neto, 1977).

Relações da erosividade com o volume das chuvas têm sido tentadas devido à maior facilidade de se obter dados pluviométricos em comparação com as maiores dificuldades na obtenção de dados pluviográficos e toda a morosidade nos procedimentos formais de se determinar a erosividade das chuvas a partir dos pluviogramas. Muitos pesquisadores têm utilizado o coeficiente de chuva (Rc), relacionando-o com a erosividade das chuvas. O coeficiente de chuva expressa para cada mês do ano, a relação entre o quadrado da precipitação média mensal $(\mathrm{Pm})$, com a média anual total $(\mathrm{Pa})$, isto é, $\mathrm{Rc}=$ $\mathrm{Pm}^{2} \mathrm{~Pa}^{-1}$. Carvalho et al. (1991), trabalhando com dados de Mococa, SP, e Roque et al. (2001), trabalhando com chuvas de Piraju, SP, obtiveram correlação potencial altamente significativa entre o coeficiente de chuva e o índice de erosividade $\mathrm{EI}_{30}$. Por outro lado, relações lineares foram obtidas por Colodro et al. (2002) para as chuvas de Teodoro Sampaio, SP, com coeficiente de correlação de $\mathrm{r}=0,963 * *$ e por Rufino et al. (1993), para oito regiões do Estado do Paraná, com coeficiente de correlação variando de $r=0,84^{*}$ a $r=0,93^{*}$.

Além da erosividade, outra importante característica relacionada com o processo de erosão hídrica do solo é o padrão hidrológico da chuva. As chuvas foram caracterizadas por Horner \& Jens (1942) em padrões hidrológicos denominados avançados, intermediários e atrasados, respectivamente quando o pico de maior intensidade da chuva ocorre no primeiro terço, no segundo terço e no terceiro terço do período de duração total da chuva. No Rio Grande do Sul, os padrões hidrológicos das chuvas foram caracterizados por Mehl et al. (2001) em Santa Maria, e por Peñalva-Bazzano et al. (2007) em Quaraí, tendo-se constatado que nos dois locais o padrão avançado é o que ocorre com maior freqüência, enquanto que Carvalho et al. (2005) no Rio de Janeiro, também encontraram o padrão avançado como o mais freqüente em Seropédica e Nova Friburgo.
O presente trabalho foi realizado com o objetivo de determinar a erosividade das chuvas pelo índice $\mathrm{EI}_{30}$, com base em um período de 29 anos (1975 a 2003), estimar o valor do Fator "R" para utilização na Equação Universal de Perdas de Solo (USLE); determinar o padrão hidrológico, o período de retorno e a probabilidade de ocorrência das chuvas erosivas para a região de Santa Rosa, RS.

\section{MATERIAL E MÉTODOS}

O município de Santa Rosa se situa entre as coordenadas geográficas de latitude $27^{\circ} 51^{\prime} \mathrm{S}$ e longitude $54^{\circ} 29^{\prime} \mathrm{W}$, na altitude de 273 m na região fisiográfica do Alto Uruguai, no noroeste do Estado do Rio Grande do Sul. Obtiveram-se os pluviogramas diários na estação agrometeorológica da FEPAGRO, localizada em Santa Rosa. O índice $\mathrm{EI}_{30}$ foi determinado para cada chuva individual e erosiva. Utilizaram-se os critérios básicos definidos por Wischmeier (1959), para caracterizar chuva individual e erosiva. De acordo com esses critérios, e para as condições brasileiras, considerou-se chuva individual aquela separada da anterior e da posterior por um período mínimo de $6 \mathrm{~h}$ sem chuva ou com menos de 1,0 mm, e chuva erosiva toda aquela com quantidade igual ou superior a 10,0 $\mathrm{mm}$ ou com 6,0 $\mathrm{mm}$ ou mais, desde que tenha ocorrido em período de $15 \mathrm{~min}$ ou menos. Analisaram-se 1.274 chuvas erosivas; no mesmo período também ocorreram 1.532 chuvas não erosivas.

Nos pluviogramas diários com as chuvas erosivas analisadas, foram separados os segmentos com a mesma inclinação, os quais representam períodos de mesma intensidade. Os dados das chuvas foram registrados manualmente em planilha, na qual se anotaram as horas e os minutos do dia em que se deu a variação de intensidade e a chuva acumulada até aquele momento. A amplitude de registro dos pluviogramas foi de $10 \mathrm{~mm}$ de precipitação, com unidade de $0,1 \mathrm{~mm}$, enquanto que o tempo de registro foi de $24 \mathrm{~h}$, com unidades de $10 \mathrm{~min}$, realizandose a leitura da precipitação com precisão de unidades de 5 minutos. Através do programa Chuveros, desenvolvido pelo Prof. Elemar Antonino Cassol, do Departamento de Solos, FA-UFRGS, se estimou a erosividade mensal, anual e média das chuvas, pelo índice $\mathrm{EI}_{30}$ (Wischmeier, 1959) no Sistema Internacional de Unidades (Foster et al., 1981). Determinou-se para cada segmento uniforme de chuva a energia cinética unitária conforme a expressão de Wischmeier \& Smith (1978) que, em unidades do sistema internacional, é dada por:

$$
\mathrm{e}=0,119+0,0873 \log _{10} \mathrm{i}
$$

onde: e é a energia cinética unitária $\left(\mathrm{MJ} \mathrm{ha}^{-1} \mathrm{~mm}^{-1}\right)$ e i é a intensidade $\left(\mathrm{mm} \mathrm{h}^{-1}\right)$ do segmento de da chuva. O valor obtido na equação (1) é multiplicado pela quantidade de chuva no respectivo segmento uniforme para expressar a energia cinética do segmento, em MJ ha- ${ }^{-1}$. Somando-se a energia cinética de todos os segmentos uniformes de chuva obtêm-se a energia cinética total da chuva $(\mathrm{ECt})$. 
A erosividade da chuva é dada pelo índice $\mathrm{EI}_{30}$, pela seguinte expressão:

$$
\mathrm{EI}_{30}=\mathrm{EC}_{\mathrm{t}} \mathrm{I}_{30}
$$

em que $\mathrm{EI}_{30}$ é o índice de erosividade da chuva individual, em MJ mm ha-1 $\mathrm{h}^{-1}, \mathrm{EC}_{\mathrm{t}}$ é a energia cinética total da chuva, em MJ ha-1 e $\mathrm{I}_{\mathbf{3 0}}$ é a intensidade máxima da chuva em um período contínuo de $30 \mathrm{~min}$ de chuva, em $\mathrm{mm} \mathrm{h}^{-1}$, ou seja, a quantidade máxima de chuva em um período contínuo de 30 minutos multiplicada por 2, definida a partir dos dados levantados do pluviograma.

Somando-se os índices $\mathrm{EI}_{30}$ de todas as chuvas individuais e erosivas de cada mês, obteve-se a erosividade mensal das chuvas em todos os meses da série analisada. Foram determinadas as médias mensais e decendiais da erosividade da chuva, necessárias para a determinação do Fator "C" (Fator de Cobertura e Manejo do Solo) da USLE. Somando-se os índices $\mathrm{EI}_{30}$ mensais de cada ano, obteve-se a erosividade anual das chuvas de todos os anos da série analisada. Fazendo-se a média da erosividade anual das chuvas no período dos 29 anos levantados (1975 a 2003), obteve-se o valor do Fator "R" da USLE para aplicação em Santa Rosa e na região do entorno com características climáticas semelhantes.

Determinaram-se os padrões hidrológicos de cada chuva erosiva analisada, seguindo a classificação proposta por Horner \& Jens (1942), que classificam as chuvas em padrões hidrológico avançado, intermediário e atrasado, respectivamente, quando a localização do pico de maior intensidade está no início (primeiro terço), meio (segundo terço) ou fim (terceiro terço) do período de duração da chuva. O programa computacional Chuveros verificava também em que tempo ocorre o pico das intensidades da chuva, para fins de classificação dos padrões hidrológicos. Calculou-se, com base no padrão hidrológico de cada chuva, a percentagem do total das chuvas que representa cada padrão hidrológico, em número, volume e erosividade.

O período de retorno e a probabilidade de ocorrência da erosividade anual foram determinados conforme Schwab et al. (1981), por meio das seguintes expressões:

$$
\begin{gathered}
T=\frac{(N+1)}{m} \\
\operatorname{Pr}=\frac{100}{T}
\end{gathered}
$$

onde: T é o período de retorno, em anos, no qual o índice de erosividade é igualado ou superado; $\mathrm{N}$ é o número de anos de registro de dados; $m$ é o número de ordem do índice de erosividade da série considerada, quando a erosividade é colocada em ordem decrescente de magnitude e Pr é a probabilidade de ocorrência do índice de erosividade, em porcentagem.

Utilizando-se os registros pluviográficos obtidos na série de dados entre 1975 e 2003, em Santa Rosa, RS, foram estabelecidas relação linear e potencial entre a erosividade das chuvas calculada pelo índice $\mathrm{EI}_{30}$, e o coeficiente de chuvas, conforme proposto por Lombardi Neto (1977) e dadas pelas seguintes expressões:

$$
\begin{gathered}
\mathrm{EI}_{30}=\mathrm{a}+\mathrm{b} \mathrm{Rc} \\
\mathrm{EI}_{30}=\mathrm{a} \mathrm{Rc}{ }^{\mathrm{b}}
\end{gathered}
$$

onde $\mathrm{EI}_{30}$ é o índice de erosividade das chuvas, $\mathrm{MJ} \mathrm{mm} \mathrm{ha}^{-1}$ $\mathrm{h}^{-1}$, a e b são coeficientes de ajuste e Rc é o coeficiente de chuva, em mm, dado pela seguinte relação: $R c=\mathrm{Pm}^{2} \mathrm{~Pa}^{-1}$, em que $\mathrm{Pm}$ é a precipitação pluvial média mensal, em mm, e Pa é a precipitação pluvial média anual, em $\mathrm{mm}$.

\section{RESULTADOS E DISCUSSÃO}

No período de 1975 a 2003, a precipitação pluvial média anual foi, em Santa Rosa, RS, de 1832 mm (Tabela 1); desse total, a quantidade média anual das chuvas erosivas foi de $1641 \mathrm{~mm}$ ano $^{-1}$ e das chuvas não erosivas, de $191 \mathrm{~mm} \mathrm{ano}^{-1}$. O ano de 1983 foi o de maior pluviosidade, com o total de chuvas de $2730 \mathrm{~mm}$, enquanto o ano de menor pluviosidade foi 1978, com 938 mm de chuva. Em relação às médias mensais, fevereiro e outubro apresentaram a maior pluviosidade média, respectivamente com 168 e 197 mm de chuva, tendo os meses de janeiro e setembro pluviosidade média muito próxima à da média do mês de fevereiro. Observa-se, por outro lado, que os meses de julho e agosto foram os de menor pluviosidade média mensal, com 124 e 129 mm de chuva, respectivamente. A variação da pluviosidade média mensal entre 124 e 197 mm de chuva, caracteriza o município de Santa Rosa, RS, como de distribuição relativamente homogênea das chuvas ao longo do ano; também se observa, na Tabela 1, a ocorrência de chuvas em todos os 348 meses do período considerado, com os valores extremos de $6,6 \mathrm{~mm}$, em novembro de 1985 e de 494 mm, em maio de 1983.

A erosividade média mensal das chuvas de Santa Rosa, $\mathrm{RS}$, avaliada pelo índice $\mathrm{EI}_{30}$, foi bastante variável, apresentando valor mínimo de $525 \mathrm{MJ} \mathrm{mm} \mathrm{ha}^{-1} \mathrm{~h}^{-1}$ no mês de julho e o máximo de $1.345 \mathrm{MJ} \mathrm{mm} \mathrm{ha}^{-1} \mathrm{~h}^{-1}$ no mês de fevereiro (Figura 1).

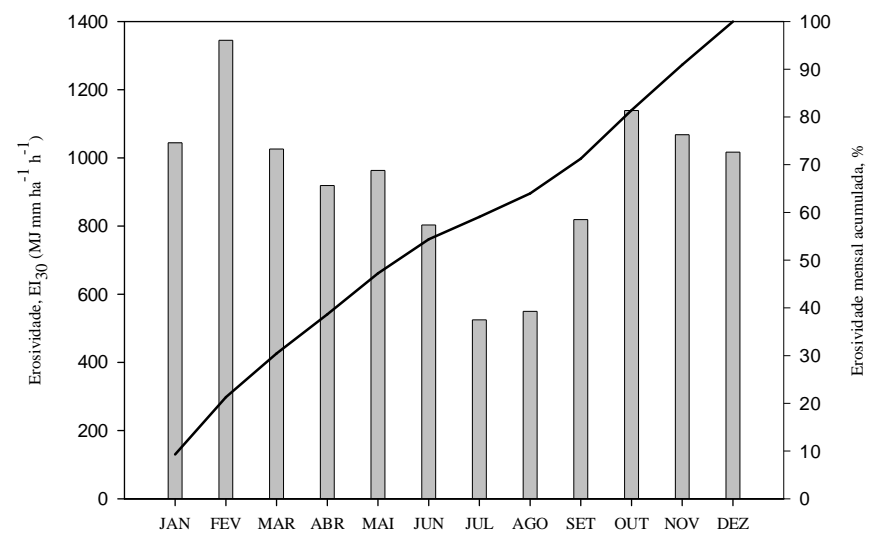

Figura 1. Erosividade média mensal das chuvas de Santa Rosa, RS, no período de 1975 a 2003, determinada pelo índice $\mathrm{El}_{30}$ 
Tabela 1. Valores mensais, anuais e médios da precipitação pluvial (mm) em Santa Rosa, RS, período 1975-2003, com as respectivas medidas estatísticas de dispersão

\begin{tabular}{|c|c|c|c|c|c|c|c|c|c|c|c|c|c|}
\hline Ano & Jan & Fev & Mar & Abr & Mai & Jun & Jul & Ago & Set & Out & Nov & Dez & Total \\
\hline 1975 & 282,5 & 88,1 & 272,9 & 176,6 & 135,3 & 167,8 & 57,0 & 136,7 & 213,0 & 78,0 & 108,2 & 196,7 & 1912,8 \\
\hline 1976 & 196,5 & 102,3 & 150,6 & 51,3 & 108,7 & 53,9 & 116,2 & 57,4 & 164,2 & 126,4 & 212,2 & 76,2 & 1415,9 \\
\hline 1977 & 149,3 & 111,5 & 60,1 & 31,5 & 101,0 & 199,3 & 230,7 & 134,2 & 149,1 & 80,5 & 199,2 & 130,9 & 1577,3 \\
\hline 1978 & 55,5 & 118,2 & 39,6 & 15,6 & 47,9 & 144,9 & 170,8 & 98,2 & 77,3 & 88,3 & 56,3 & 25,6 & 938,2 \\
\hline 1979 & $161,4^{*}$ & $167,9 *$ & $145,1^{*}$ & $154,9 *$ & $157,7^{*}$ & 40,1 & 193,4 & 150,0 & 172,1 & 313,7 & 50,8 & 255,9 & 1963,0 \\
\hline 1980 & 110,6 & 64,4 & 188,2 & 74,7 & 333,8 & 52,0 & 62,8 & 66,1 & 119,6 & 209,2 & 244,9 & 95,1 & 1621,4 \\
\hline 1981 & $161,4^{*}$ & $167,9 *$ & $145,1^{*}$ & $154,9 *$ & $157,7^{*}$ & $152,1^{*}$ & 16,2 & 27,9 & 231,0 & 44,1 & 206,4 & 130,2 & 1594,9 \\
\hline 1982 & 40,4 & 234,1 & 83,3 & 50,2 & 85,8 & 268,9 & 184,5 & 305,9 & 150,2 & 224,5 & 359,2 & 129,4 & 2116,4 \\
\hline 1983 & 318,2 & 238,5 & 220,2 & 372,7 & 494,2 & 139,8 & 363,5 & 144,6 & 113,9 & 167,9 & 94,3 & 62,6 & 2730,4 \\
\hline 1984 & 156,0 & 119,0 & 131,8 & 143,8 & 352,8 & 166,9 & 173,1 & 261,9 & 213,5 & 239,5 & 174,6 & 92,2 & 2225,1 \\
\hline 1985 & $161,4^{*}$ & 236,1 & 309,0 & 227,0 & 276,2 & 156,1 & 123,3 & 354,8 & 123,6 & 88,0 & 6,6 & 7,5 & 2069,6 \\
\hline 1986 & 98,5 & 131,1 & 251,2 & 403,6 & 197,2 & 184,4 & 50,0 & 142,2 & 130,1 & 189,1 & 387,5 & 46,0 & 2210,9 \\
\hline 1987 & 139,1 & 332,8 & 64,8 & 315,0 & 209,7 & 121,6 & 338,2 & 116,7 & 225,7 & 107,9 & 118,3 & 110,5 & 2200,3 \\
\hline 1988 & $161,4^{*}$ & $167,9 *$ & $145,1^{*}$ & $154,9 *$ & $157,7^{*}$ & $152,1^{*}$ & $124,1^{*}$ & $129,3^{*}$ & $160,6^{*}$ & $196,7^{*}$ & $147,2^{*}$ & $135,5^{*}$ & 1832,5 \\
\hline 1989 & 233,5 & 58,0 & 81,0 & 195,2 & 31,0 & 190,1 & 78,6 & 230,2 & 252,2 & 186,2 & 91,2 & 164,9 & 1792,1 \\
\hline 1990 & $161,4^{*}$ & $167,9^{*}$ & $145,1^{*}$ & $154,9 *$ & $157,7^{*}$ & $152,1^{*}$ & $124,1^{*}$ & $129,3^{*}$ & $160,6^{*}$ & $196,7^{*}$ & $147,2^{*}$ & $135,5^{*}$ & 1832,5 \\
\hline 1991 & 73,1 & 32,2 & 116,2 & 143,1 & 73,4 & 295,1 & 82,8 & 17,0 & 64,2 & 133,8 & 48,6 & 297,5 & 1377,0 \\
\hline 1992 & 32,1 & 333,0 & 153,5 & 208,1 & 296,8 & 272,5 & 59,2 & 96,5 & 155,4 & 239,0 & 132,3 & 29,3 & 2007,7 \\
\hline 1993 & 263,4 & 56,6 & 255,0 & 61,2 & 103,6 & 115,8 & 143,2 & 25,8 & 167,7 & 187,3 & 244,9 & 119,1 & 1743,6 \\
\hline 1994 & 182,3 & 284,7 & 56,7 & 223,0 & 243,9 & 209,4 & 126,5 & 56,5 & 152,7 & 252,2 & 156,6 & 137,6 & 2082,1 \\
\hline 1995 & 213,2 & 108,2 & 122,7 & 30,6 & 49,7 & 104,2 & 80,9 & 53,8 & 103,5 & 204,2 & 20,5 & 45,9 & 1137,4 \\
\hline 1996 & 213,5 & 268,0 & 48,9 & 92,1 & 75,4 & 53,5 & 62,9 & 183,4 & 67,0 & 391,4 & 73,9 & 254,8 & 1784,8 \\
\hline 1997 & 143,2 & 210,8 & 15,2 & 100,5 & 100,0 & 151,4 & 65,8 & 226,3 & 121,9 & 459,1 & 304,3 & 344,9 & 2243,4 \\
\hline 1998 & 226,1 & 279,9 & 216,7 & 333,3 & 69,8 & 116,9 & 124,3 & 189,3 & 108,3 & 238,1 & 36,3 & 93,2 & 2032,2 \\
\hline 1999 & 54,5 & 206,6 & 139,9 & 122,4 & 95,5 & 51,9 & 108,9 & 19,6 & 337,4 & 165,6 & 70,8 & 110,8 & 1483,9 \\
\hline 2000 & 76,4 & 114,3 & 173,1 & 79,9 & $157,7^{*}$ & 243,3 & 63,7 & 106,4 & 159,8 & 295,7 & 63,8 & 207,4 & 1741,5 \\
\hline 2001 & 240,4 & 147,8 & 177,5 & 107,4 & 139,8 & 98,2 & 95,9 & 48,0 & 191,8 & 122,7 & 152,7 & 52,3 & 1574,5 \\
\hline 2002 & 176,2 & 82,2 & 201,4 & 101,0 & 152,0 & 205,4 & 81,5 & 193,2 & 309,2 & 389,6 & 226,6 & 305,0 & 2423,3 \\
\hline 2003 & 199,5 & 238,0 & 98,5 & 213,9 & 9,0 & $152,1^{*}$ & 96,8 & 47,7 & 61,2 & 88,8 & 132,1 & $135,5^{*}$ & 1473,1 \\
\hline Média & 161,4 & 167,9 & 145,1 & 154,9 & 157,6 & 152,1 & 124,1 & 129,3 & 160,6 & 196,7 & 147,2 & 135,4 & 1832,3 \\
\hline $\mathrm{DP}$ & 77,78 & 88,61 & 77,62 & 104,04 & 110,85 & 72,20 & 81,42 & 88,75 & 72,19 & 105,75 & 99,48 & 89,68 & 507,17 \\
\hline $\mathrm{CV}(\%)$ & 48,19 & 52,79 & 53,49 & 67,15 & 70,33 & 47,46 & 65,61 & 68,66 & 44,95 & 53,76 & 67,61 & 66,21 & 27,68 \\
\hline MÁX & 318,2 & 333,0 & 309,0 & 403,6 & 494,2 & 295,1 & 363,5 & 354,8 & 337,4 & 459,1 & 387,5 & 344,9 & 2730,4 \\
\hline MÍN & 32,1 & 32,2 & 15,2 & 15,6 & 9,0 & 40,1 & 16,2 & 17,0 & 61,2 & 44,1 & 6,6 & 7,5 & 938,2 \\
\hline
\end{tabular}

DP - Desvio padrão; CV - Coeficiente de variação; MÁX - Valor máximo da série; MíN - Valor mínimo da série;

*Significa que o valor não foi observado devido à inexistência do dado de chuva, tendo-se utilizado o valor médio do referido mês da série levantada

Os maiores valores médios mensais do índice $\mathrm{EI}_{30}$ se concentram de outubro a março, entre 1.017 e $1.345 \mathrm{MJ} \mathrm{mm}$ $\mathrm{ha}^{-1} \mathrm{~h}^{-1}$ mês ${ }^{-1}$; já os menores valores do índice $\mathrm{EI}_{30}$, se concentram nos meses de julho e agosto, respectivamente, com valores de 525 e $550 \mathrm{MJ} \mathrm{mm} \mathrm{ha}^{-1} \mathrm{~h}^{-1}$ mês $^{-1}$. Quanto às estações climáticas e se considerando a primavera-verão entre outubro e março e o outono-inverno entre abril e setembro, nota-se que 59,2\% da erosividade das chuvas de Santa Rosa se concentra no período de primavera-verão, enquanto $40,8 \%$ do total da erosividade das chuvas se concentram no período de outono-inverno. De maneira geral, os meses de inverno apresentam valores mais baixos de erosividade das chuvas, especialmente julho e agosto, enquanto os meses de verão têm valores mais altos de erosividade média, especialmente o mês de fevereiro (Figura 1). Valores baixos de erosividade das chuvas nos meses de inverno também foram encontrados, dentre outros, por Peñalva-Bazzano et al. (2007) em Quaraí, RS, por Cogo et al. (2006), em Santa Maria, RS, por Moreti et al. (2003), em São Manuel, SP, por Marques et al. (1998) em Sete Lagoas, MG, por Bertol (1993), em Lages, SC, por Morais et al. (1991) no sudoeste do MT e por Carvalho et al. (1991) em Mococa, SP.

Na região de Santa Rosa, RS, a principal cultura de verão é a soja; entre outubro e dezembro ocorre o preparo do solo e a semeadura da cultura; neste período a erosividade das chuvas é elevada, atingindo valores entre 1.017 e $1.139 \mathrm{MJ}$ $\mathrm{mm} \mathrm{ha}^{-1} \mathrm{~h}^{-1} \mathrm{mês}^{-1}$ (Figura 1), e com o solo mais exposto e alta erosividade das chuvas, os cuidados no controle da erosão deverão ser ainda maiores. O pico mensal mais notável na erosividade das chuvas em Santa Rosa ocorre no mês de fevereiro, no qual, normalmente, as culturas de verão estão em pleno desenvolvimento, mantendo o solo quase que totalmente coberto, protegido do potencial erosivo das chuvas. Devese ter cuidados também nos meses de março a junho, período em que ocorre o preparo do solo e a semeadura das culturas anuais de ciclo de inverno, no qual a erosividade das chuvas atinge valores intermediários, isto é, entre 803 e 1.026 MJ mm ha ${ }^{-1} \mathrm{~h}^{-1}$ mês $^{-1}$ (Figura 1). 
Individualmente, o mês em que ocorreu a maior erosividade, foi novembro de 1986, dentre os 348 meses da série levantada, com valor de 4.160,4 MJ mm ha ${ }^{-1} \mathrm{~h}^{-1}$ mês $^{-1}$ (Tabela 2 ), proveniente de nove chuvas erosivas ocorridas, que totalizaram um volume de chuva de $376,9 \mathrm{~mm}$, do total de 387,5 $\mathrm{mm}$ de chuva constatada naquele mês (Tabela 1). Esses picos excepcionais na erosividade das chuvas são responsáveis por grandes danos nas lavouras cultivadas pela ocorrência do processo de erosão hídrica. Observa-se, na Tabela 2, que em alguns poucos meses da série levantada o valor da erosividade das chuvas foi zero; por outra parte, se verifica, na Tabela 1, que em nenhum mês da série considerada ocorreu zero de precipitação pluvial, evidenciando que nos meses de erosividade zero as chuvas que ocorreram não foram erosivas. Nota-se na Tabela 2 que, de maneira geral, com algumas poucas exceções, os valores mensais da erosividade das chuvas normalmente são elevados.

A erosividade anual das chuvas no período do estudo, em Santa Rosa, variou de 3.295 (em 1978) a 19.343 MJ mm ha-1 $\mathrm{h}^{-1}$ ano $^{-1}$ (em 1997), sendo de 11.217 MJ mm ha-1 $\mathrm{h}^{-1}$ ano $^{-1} \mathrm{o}$ valor médio obtido (Figura 2). O valor médio anual de 11.217 MJ $\mathrm{mm} \mathrm{ha}^{-1} \mathrm{~h}^{-1}$ para a erosividade das chuvas, apresentou

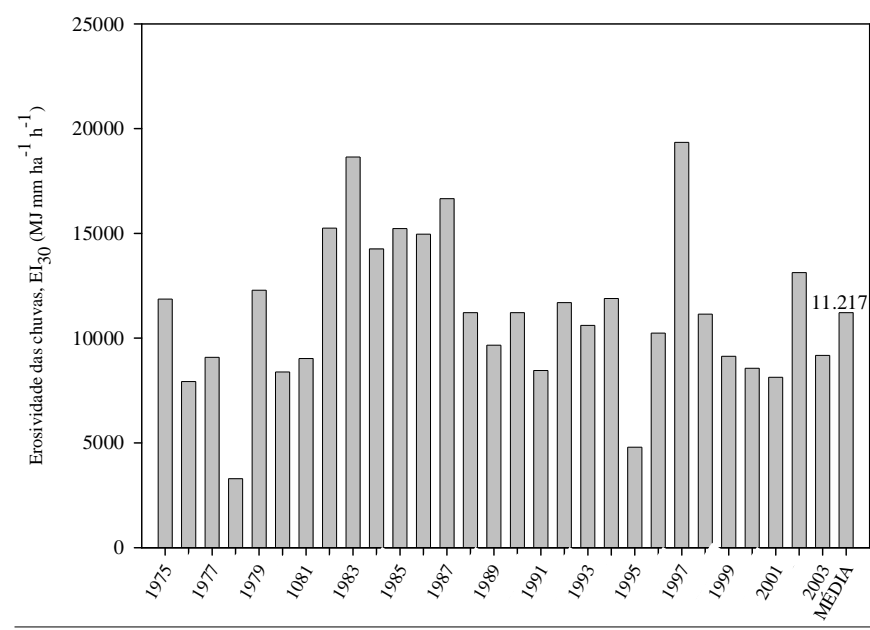

Figura 2. Erosividade anual das chuvas de Santa Rosa, RS, determinada pelo índice $\mathrm{El}_{30}$, no período de 1975 a 2003

Tabela 2. Valores mensais, anuais e médios do índice de erosividade $\mathrm{El}_{30}\left(\mathrm{MJ} \mathrm{mm} \mathrm{ha-1} \mathrm{h}^{-1}\right.$ ) em Santa Rosa, RS, período 1975-2003, e as respectivas medidas estatísticas de dispersão

\begin{tabular}{|c|c|c|c|c|c|c|c|c|c|c|c|c|c|}
\hline Ano & Jan & Fev & Mar & $A b r$ & Mai & Jun & Jul & Ago & Set & Out & Nov & Dez & Total \\
\hline 1975 & 1804,7 & 488,7 & 2885,3 & 602,6 & 1109,5 & 1197,5 & 60,8 & 268,4 & 1082,2 & 177,3 & 699,9 & 1486,6 & 11863,5 \\
\hline 1976 & 1134,9 & $1.046,4$ & 1087,0 & 265,6 & 413,4 & 43,9 & 534,1 & 21,5 & 859,5 & 498,9 & 1713,5 & 310,4 & 7929,1 \\
\hline 1977 & 455,8 & 629,2 & 279,3 & 51,1 & 440,2 & 1367,6 & 1417,0 & 470,3 & 1388,5 & 313,1 & 1394,1 & 880,5 & 9086,7 \\
\hline 1978 & 36,7 & 1122,5 & 129,2 & 0,0 & 178,5 & 584,4 & 547,7 & 213,9 & 83,1 & 168,0 & 231,0 & 0,0 & 3295,0 \\
\hline 1979 & $1044,0 *$ & $1345,0 *$ & $1025,9 *$ & $918,8^{*}$ & $962,5^{*}$ & 36,9 & 929,2 & 378,7 & 1126,1 & $2.208,2$ & 237,6 & $2.072,5$ & 12285,4 \\
\hline 1980 & 553,6 & 269,7 & 1317,7 & 204,8 & 1693,9 & 62,2 & 99,3 & 222,5 & 390,2 & 707,8 & 2399,4 & 463,4 & 8384,5 \\
\hline 1981 & $1044,0 *$ & $1345,0 *$ & $1025,9 *$ & $918,8 *$ & $962,5^{*}$ & $803,0 *$ & 0,0 & 17,3 & 1047,4 & 117,3 & 1208,6 & 541,3 & 9031,1 \\
\hline 1982 & 246,0 & 2469,6 & 724,5 & 98,8 & 292,0 & 2564,1 & 451,8 & 2147,1 & 404,9 & 1005,8 & 2959,3 & 1885,5 & 15249,4 \\
\hline 1983 & 3109,8 & 2633,7 & 1371,7 & 3367,3 & 2802,5 & 788,1 & 1814,2 & 559,5 & 614,1 & 1252,9 & 171,0 & 163,8 & 18648,6 \\
\hline 1984 & 337,2 & 547,5 & 476,9 & 1085,6 & 2974,5 & 650,7 & 1369,6 & 1312,6 & 2193,1 & 1912,8 & 872,6 & 527,3 & 14260,4 \\
\hline 1985 & $1044,0 *$ & 2863,5 & 3699,9 & 1739,9 & 2751,0 & 1039,1 & 147,5 & 1448,0 & 188,9 & 309,1 & 0,0 & 0,0 & 15230,9 \\
\hline 1986 & 503,7 & 749,5 & 2367,8 & 2286,0 & 1480,4 & 646,3 & 219,9 & 753,2 & 392,3 & 1188,7 & 4160,4 & 217,6 & 14965,8 \\
\hline 1987 & 589,4 & 3434,6 & 659,3 & 2817,8 & 1168,1 & 349,4 & 2487,0 & 822,5 & 1624,6 & 384,2 & 961,0 & 1361,0 & 16658,9 \\
\hline 1988 & $1044,0 *$ & $1345,0 *$ & $1025,9 *$ & $918,8^{*}$ & $962,5^{*}$ & $803,0 *$ & $524,5^{*}$ & $550,1^{*}$ & $819,5^{*}$ & $1138,7^{*}$ & $1067,6^{*}$ & $1017,4^{*}$ & 11217,0 \\
\hline 1989 & 1757,1 & 300,2 & 363,0 & 1456,5 & 93,8 & 651,2 & 179,9 & 1001,5 & 1396,2 & 671,0 & 430,8 & 1364,1 & 9665,3 \\
\hline 1990 & $1044,0 *$ & $1345,0 *$ & $1025,9 *$ & $918,8^{*}$ & $962,5^{*}$ & $803,0 *$ & $524,5^{*}$ & $550,1^{*}$ & $819,5^{*}$ & $1138,7^{*}$ & $1067,6^{*}$ & $1017,4^{*}$ & 11217,0 \\
\hline 1991 & 414,5 & 225,3 & 948,6 & 899,7 & 270,5 & 1690,7 & 202,7 & 27,0 & 163,9 & 778,7 & 22,3 & 2809,4 & 8453,3 \\
\hline 1992 & 50,2 & 2270,9 & 936,9 & 1079,3 & 2501,8 & 1647,8 & 113,8 & 148,0 & 596,8 & 1406,5 & 807,6 & 133,4 & 11693,0 \\
\hline 1993 & 2139,3 & 453,0 & 2050,0 & 287,1 & 548,0 & 351,1 & 573,8 & 37,0 & 673,3 & 1070,6 & 1835,5 & 587,7 & 10606,4 \\
\hline 1994 & 1228,7 & 1376,3 & 150,5 & 1146,0 & 1866,9 & 1855,9 & 331,4 & 123,7 & 740,3 & 1053,2 & 559,1 & 1463,2 & 11895,2 \\
\hline 1995 & 1632,0 & 411,1 & 434,4 & 43,0 & 119,2 & 622,6 & 203,3 & 40,2 & 175,0 & 970,8 & 23,4 & 116,4 & 4791,4 \\
\hline 1996 & 1320,0 & 2179,4 & 241,0 & 394,5 & 101,8 & 96,6 & 113,0 & 659,8 & 87,5 & 3059,5 & 203,8 & 1783,2 & 10240,1 \\
\hline 1997 & 1465,2 & 1853,1 & 0,0 & 649,6 & 173,9 & 1145,9 & 138,0 & 2845,5 & 503,2 & 3445,4 & 4011,3 & 3112,0 & 19343,1 \\
\hline 1998 & 2929,9 & 2167,4 & 814,3 & 1469,8 & 240,7 & 334,6 & 269,1 & 423,2 & 218,8 & 1754,0 & 59,8 & 465,2 & 11146,8 \\
\hline 1999 & 155,0 & 3141,9 & 1057,6 & 597,8 & 297,5 & 60,1 & 166,7 & 25,0 & 2636,3 & 522,2 & 151,6 & 326,0 & 9137,7 \\
\hline 2000 & 117,5 & 364,4 & 1087,6 & 182,9 & $962,5^{*}$ & 839,9 & 133,1 & 297,6 & 1012,7 & 2131,8 & 318,9 & 1110,7 & 8559,6 \\
\hline 2001 & 1124,7 & 639,7 & 1282,6 & 583,6 & 556,1 & 720,8 & 564,1 & 25,9 & 850,5 & 392,1 & 1261,7 & 127,6 & 8129,4 \\
\hline 2002 & 610,8 & 262,8 & 965,2 & 241,6 & 1026,3 & 728,6 & 137,9 & 514,1 & 1483,8 & 2494,8 & 1520,6 & 3143,6 & 13130,1 \\
\hline 2003 & 1338,7 & 1723,4 & 317,2 & 1419,5 & 0,0 & $803,0 *$ & 957,6 & 49,2 & 188,8 & 750,6 & 611,7 & $1017,4^{*}$ & 9177,1 \\
\hline $\mathrm{DP}$ & 795,5 & 971,7 & 839,3 & 829,3 & 885,8 & 602,8 & 584,4 & 663,1 & 634,5 & 875,6 & 1112,0 & 915,8 & 4163,6 \\
\hline $\mathrm{CV}(\%)$ & 76,2 & 72,2 & 81,8 & 90,3 & 92,0 & 75,1 & 111,4 & 120,5 & 77,4 & 76,9 & 104,2 & 90,0 & 37,1 \\
\hline MÁX & 3109,8 & 3434,6 & 3699,9 & 3367,3 & 2974,5 & 2564,1 & 2487,0 & 2845,5 & 2636,3 & 3445,4 & 4160,4 & 3143,6 & 19343,1 \\
\hline MíN & 36,7 & 225,3 & 0,0 & 0,0 & 0,0 & 36,9 & 0,0 & 17,3 & 83,1 & 117,3 & 0,0 & 0,0 & 3295,0 \\
\hline
\end{tabular}

DP - Desvio padrão; CV - Coeficiente de variação; MÁX - Valor máximo da série; MíN - Valor mínimo da série;

*Significa que o valor não foi observado devido à inexistência do dado de chuva, tendo-se utilizado o valor médio do referido mês da série levantada 
um desvio padrão de 4.163,6 $\mathrm{MJ} \mathrm{mm} \mathrm{ha}^{-1} \mathrm{~h}^{-1}$ e um coeficiente de variação de $37,1 \%$ (Tabela 2 ).

O valor do Fator "R" da USLE para Santa Rosa, RS, é de 11.271 $\mathrm{MJ} \mathrm{mm} \mathrm{ha}^{-1} \mathrm{~h}^{-1}$ ano $^{-1}$ (Figura 2), que representa a erosividade média anual das chuvas do local, com base no período de 29 anos da série levantada (1975 a 2003); este valor do fator "R" da USLE pode ser utilizado com segurança para localidades próximas, no entorno de Santa Rosa, com características climáticas semelhantes, especialmente nos 24 municípios que compõem a sub-região agroecológica 7C (Rio Grande do Sul, 1994); dessa forma, amplia-se a possibilidade da utilização da Equação Universal de Perdas de Solo no planejamento conservacionista da atividade agrícola.

Obteve-se relação linear e potencial entre o coeficiente de chuvas (Rc) e a erosividade das chuvas (expresso pelo índice $\mathrm{EI}_{30}$ ), dadas pelas seguintes expressões:

$$
\begin{array}{ll}
\mathrm{EI}_{30}=354,71+44,927 \mathrm{Rc} & \mathrm{R}^{2}=0,4131 \\
\mathrm{EI}_{30}=118,52 \mathrm{Rc}^{0,8034} & \mathrm{R}^{2}=0,5053
\end{array}
$$

onde $\mathrm{EI}_{30}$ é o índice de erosividade da chuva (MJ mm ha-1 $\left.\mathrm{h}^{-1}\right)$ e Rc é o coeficiente de chuva ( $\left.\mathrm{mm}\right)$.

Tanto a relação linear (Eq. 7), quanto a relação potencial (Eq. 8) apresentaram baixo coeficiente de regressão entre o índice $\mathrm{EI}_{30}$ e o coeficiente de chuvas (Rc); entretanto, para o valor médio anual (valor "R" da Equação Universal de Perdas de Solo - USLE), o somatório dos valores estimados pela relação linear (Eq. 7) mostra uma excelente aproximação com o valor observado (Tabela 3); desta forma, se conclui que, para o valor do Fator "R" na região de Santa Rosa, RS, pode-se utilizar dados pluviométricos e estimativa pela relação linear para obtenção do fator "R" da USLE (Equação Universal de Perdas de Solo), pelo índice $\mathrm{EI}_{30}$, especialmente nos 24 municípios que compõem a sub-região agroecológica 7C (Rio Grande do Sul, 1994), com características climáticas semelhantes e que não possuam dados pluviográficos disponíveis. Entretanto, essas relações são inadequadas para se determinar a dis- tribuição mensal do índice de erosividade, cujos resultados diferem dos demonstrados por vários pesquisadores que encontraram correlações significativas entre o índice de erosividade $\mathrm{EI}_{30}$ e o coeficiente de chuva Rc, entre os quais estão os resultados de Carvalho et al. (1991), que obtiveram relação potencial $\left(\mathrm{EI}_{30}=111,173 \mathrm{Rc}^{0,691}\right)$ altamente significativa $(\mathrm{r}=0,991 * *)$, em Mococa, $\mathrm{SP}$, de Rufino et al. (1993), que obtiveram relação linear para oito regiões do Estado do Paraná, com coeficiente de correlação variando de $r=0,84^{*}$ a $r=0,93 *$ e de Peñalva Bazzano et al. (2007) que obtiveram correlação linear significativa $\left(\mathrm{EI}_{30}=-47,35\right.$ + 82,72 Rc) em Quaraí, RS.

Para utilização da Equação Universal de Perdas de Solo no planejamento agrícola conservacionista, também se deve conhecer o Fator " $C$ " da USLE; para que o Fator " $C$ " possa ser calculado, é necessário que se determinem as médias decendiais e mensais da erosividade das chuvas. $\mathrm{Na}$ Tabela 4 se apresentam as médias decendiais e mensais da erosividade das chuvas de Santa Rosa, RS. O Fator "C" da USLE em determinado decêndio, será obtido através do produto entre a porcentagem acumulada de seu $\mathrm{EI}_{30}$ e a correspondente razão de perda de solo, para certo uso e manejo. Obtendo-se desta forma os 36 produtos equivalentes a cada decêndio, o Fator " $C$ " final será determinado através do somatório dos produtos acima referidos, conforme preconizado por Wischmeier \& Smith (1978); estes referidos dados facilitam a obtenção do fator $\mathrm{C}$ para as diversas culturas e aumentam a possibilidade de uso da USLE.

Constata-se na Tabela 5 o período de retorno e a probabilidade de ocorrência de todos os eventos de erosividade anual do período de 1975 a 2003, em Santa Rosa, RS. O maior valor anual, de $19.343 \mathrm{MJ} \mathrm{mm} \mathrm{ha}{ }^{-1} \mathrm{~h}^{-1}$, tem um período de retorno estimado em 30 anos com probabilidade de ocorrência de $3,3 \%$, enquanto a menor erosividade anual do período, de $3.295 \mathrm{MJ} \mathrm{mm} \mathrm{ha}^{-1} \mathrm{~h}^{-1}$, tem um período de retorno estimado em um ano, com 93,3\% de probabilidade de ocorrência. Da

Tabela 3. Relação linear e potencial da quantidade de precipitação pluvial (mm) com a erosividade das chuvas em Santa Rosa, RS, no

\begin{tabular}{|c|c|c|c|c|c|c|c|c|}
\hline \multirow{3}{*}{ Mês } & \multirow{3}{*}{$\begin{array}{l}\text { Chuva Média } \\
\text { Mensal } \\
\text { mm }\end{array}$} & \multirow{3}{*}{$\begin{array}{c}\text { Coeficiente de } \\
\text { Chuva }-\mathbf{R c}^{*} \\
\text { mm }\end{array}$} & \multirow{2}{*}{\multicolumn{2}{|c|}{$\mathrm{El}_{30}$ Observado }} & \multicolumn{4}{|c|}{$\mathrm{El}_{30}$ Calculado } \\
\hline & & & & & \multicolumn{2}{|c|}{ Eq. 7} & \multicolumn{2}{|c|}{ Eq. 8} \\
\hline & & & $\begin{array}{l}\text { Absoluto } \\
\text { MJ mm ha } \mathrm{ha}^{-1} \mathrm{~h}^{-1}\end{array}$ & $\begin{array}{c}\text { Relativo } \\
\%\end{array}$ & $\begin{array}{c}\text { Absoluto } \\
\text { MJ mm ha-1 } h^{-1}\end{array}$ & $\begin{array}{c}\text { Relativo } \\
\%\end{array}$ & $\begin{array}{l}\text { Absoluto } \\
\text { MJ mm ha-1 } h^{-1}\end{array}$ & $\begin{array}{c}\text { Relativo } \\
\%\end{array}$ \\
\hline J an & 161,4 & 14,22 & $1.044,0$ & 9,31 & 993,4 & 8,86 & 999,9 & 9,05 \\
\hline Fev & 167,9 & 15,39 & $1.345,0$ & 11,99 & $1.045,9$ & 9,32 & $1.065,4$ & 9,64 \\
\hline Mar & 145,1 & 11,49 & $1.025,9$ & 9,15 & 870,9 & 7,76 & 842,7 & 7,62 \\
\hline Abr & 154,9 & 13,10 & 918,8 & 8,19 & 943,0 & 8,41 & 936,0 & 8,47 \\
\hline Mai & 157,6 & 13,56 & 962,5 & 8,58 & 963,7 & 8,59 & 962,4 & 8,71 \\
\hline J un & 152,1 & 12,63 & 803,0 & 7,16 & 922,0 & 8,22 & 909,0 & 8,22 \\
\hline Jul & 124,1 & 8,41 & 524,5 & 4,68 & 732,3 & 6,53 & 655,5 & 5,93 \\
\hline Ago & 129,3 & 9,12 & 550,1 & 4,90 & 764,6 & 6,82 & 700,2 & 6,33 \\
\hline Set & 160,6 & 14,08 & 819,3 & 7,30 & 987,1 & 8,80 & 992,0 & 8,97 \\
\hline Out & 196,7 & 21,12 & $1.138,7$ & 10,15 & $1.303,4$ & 11,62 & $1.374,0$ & 12,43 \\
\hline Nov & 147,2 & 11,83 & $1.067,6$ & 9,52 & 886,0 & 7,90 & 862,4 & 7,80 \\
\hline Dez & 135,4 & 10,01 & $1.017,4$ & 9,07 & 804,2 & 7,17 & 754,0 & 6,82 \\
\hline Tot & $1.832,3$ & - & $11.216,8$ & 100,0 & $11.216,7$ & 100,0 & $11.053,3$ & 100,0 \\
\hline
\end{tabular}
período 1975 a 2003

$\mathrm{Rc}=\mathrm{Pm}^{2} \mathrm{~Pa}^{-1} \quad$ onde $\mathrm{Pm}=$ precipitação média mensal $(\mathrm{mm})$ e $\mathrm{Pa}=$ precipitação média anual $(\mathrm{mm})$ 
Tabela 4. Distribuição média decendial e mensal dos valores absolutos e relativos do Fator "R" de Santa Rosa, RS, no período de 1975 a 2003

\begin{tabular}{|c|c|c|c|c|c|}
\hline \multirow{3}{*}{ Mês } & \multirow{3}{*}{$\begin{array}{c}\text { Decêndio } \\
\text { mensal }\end{array}$} & \multicolumn{4}{|c|}{ Valor do índice de erosividade El30 } \\
\hline & & \multicolumn{2}{|c|}{ Decendial } & \multicolumn{2}{|c|}{ Mensal } \\
\hline & & Absoluto & Relativo & Absoluto & Relativo \\
\hline \multirow{3}{*}{ Jan } & $1^{0}$ & 207,4 & 1,85 & & \\
\hline & $2^{\circ}$ & 293,2 & 2,61 & $1.044,0$ & 9,31 \\
\hline & $3^{\circ}$ & 543,4 & 4,84 & & \\
\hline \multirow{3}{*}{ Fev } & $1^{0}$ & 572,8 & 5,11 & & \\
\hline & $2^{\circ}$ & 347,6 & 3,10 & $1.344,9$ & 11,99 \\
\hline & $3^{\circ}$ & 424,5 & 3,78 & & \\
\hline & $1^{\circ}$ & 291,4 & 2,60 & & \\
\hline \multirow[t]{2}{*}{ Mar } & $2^{0}$ & 285,3 & 2,54 & $1.025,9$ & 9,15 \\
\hline & $3^{\circ}$ & 449,3 & 4,01 & & \\
\hline \multirow{3}{*}{ Abr } & $1^{0}$ & 268,8 & 2,40 & & \\
\hline & $2^{\circ}$ & 389,0 & 3,47 & 918,8 & 8,19 \\
\hline & $3^{\circ}$ & 261,0 & 2,33 & & \\
\hline \multirow{3}{*}{ Mai } & $1^{\circ}$ & 313,6 & 2,80 & & \\
\hline & $2^{\circ}$ & 299,9 & 2,67 & 962,5 & 8,58 \\
\hline & $3^{\circ}$ & 349,1 & 3,11 & & \\
\hline \multirow{3}{*}{ Jun } & $1^{0}$ & 349,0 & 3,11 & & \\
\hline & $2^{\circ}$ & 227,0 & 2,02 & 803,0 & 7,1 \\
\hline & $3^{\circ}$ & 227,1 & 2,02 & & \\
\hline \multirow{3}{*}{ Jul } & $1^{0}$ & 269,4 & 2,40 & & \\
\hline & $2^{0}$ & 80,0 & 0,71 & 524,5 & 4,68 \\
\hline & $3^{\circ}$ & 175,1 & 1,56 & & \\
\hline & $1^{\circ}$ & 260,4 & 2,32 & & \\
\hline \multirow[t]{2}{*}{ Ago } & $2^{0}$ & 110,9 & 0,99 & 550,1 & 4,90 \\
\hline & $3^{\circ}$ & 178,9 & 1,59 & & \\
\hline & $1^{0}$ & 167,5 & 1,49 & & \\
\hline \multirow[t]{2}{*}{ Set } & $2^{\circ}$ & 389,6 & 3,47 & 819,3 & 7,30 \\
\hline & $3^{\circ}$ & 262,2 & 2,34 & & \\
\hline & $1^{\circ}$ & 419,5 & 3,74 & & \\
\hline \multirow[t]{3}{*}{ Out } & $2^{\circ}$ & 360,2 & 3,21 & $1.138,7$ & 10,15 \\
\hline & $3^{\circ}$ & 359,0 & 3,20 & & \\
\hline & $1^{\circ}$ & 464,4 & 4,14 & & \\
\hline \multirow[t]{3}{*}{ Nov } & $2^{\circ}$ & 266,5 & 2,38 & $1.067,7$ & 9,52 \\
\hline & $3^{\circ}$ & 336,8 & 3,00 & & \\
\hline & $1^{0}$ & 242,2 & 2,16 & & \\
\hline \multirow[t]{2}{*}{ Dez } & $2^{\circ}$ & 346,3 & 3,09 & $1.017,4$ & 9,07 \\
\hline & $3^{\circ}$ & 428,9 & 3,82 & & \\
\hline Total & - & $11.217,0$ & 100,0 & $11.217,0$ & 100,0 \\
\hline
\end{tabular}

mesma forma se observa que o valor médio da erosividade anual do período considerado, de $11.217 \mathrm{MJ} \mathrm{mm} \mathrm{ha}^{-1}$ $\mathrm{h}^{-1}$ (que é o valor do Fator "R" da USLE em Santa Rosa, RS), tem um período de retorno estimado de 2,3 anos com $43,3 \%$ de probabilidade de ocorrência. Colodro et al. (2002), ao analisarem uma série de 19 anos de dados de Teodoro Sampaio (SP), notaram que o valor determinado para o Fator "R" da USLE, tem um período de retorno de 2,33 anos, com 42,9\% de probabilidade de ocorrência.

Na média anual, a distribuição dos padrões hidrológico avançado, intermediário e atrasado é, respectivamente, de 52, 24 e $24 \%$ para o número de chuvas erosivas, 58, 23 e $19 \%$ para a quantidade média de chuvas e 62,21 e $17 \%$ para a erosividade média anual (Tabela 6). Peñalva-Bazzano et al. (2007) obtiveram, na erosividade média anual das chuvas, respectivamente, 57,25 e $18 \%$ nos padrões avançado, inter-
Tabela 5. Período de retorno e probabilidade de ocorrência dos valores dos índices anuais de erosividade $\left(\mathrm{El}_{30}\right)$, de Santa Rosa (RS) durante o período de 1975 a 2003

\begin{tabular}{ccccc} 
Ano & $\begin{array}{c}\text { Índice de } \\
\text { Erosividade } \\
\text { (El30) } \\
\text { (M) }{\text { mm ha } \mathbf{~ h}^{-1} \text { ) }}^{-1}\end{array}$ & $\begin{array}{c}\text { Número de } \\
\text { Ordem (m) }\end{array}$ & $\begin{array}{c}\text { Período de } \\
\text { Retorno (T) }\end{array}$ & $\begin{array}{c}\text { Probabilidade } \\
\text { de Ocorrência } \\
\text { (T) }\end{array}$ \\
\hline 1997 & $19.343,1$ & 1 & 30,0 & 3,3 \\
1983 & $18.648,6$ & 2 & 15,0 & 6,7 \\
1987 & $16.658,9$ & 3 & 10,0 & 10,0 \\
1982 & $15.249,4$ & 4 & 7,5 & 13,3 \\
1985 & $15.230,9$ & 5 & 6,0 & 16,7 \\
1986 & $14.965,8$ & 6 & 5,0 & 20,0 \\
1984 & $14.260,4$ & 7 & 4,3 & 23,3 \\
2002 & $13.130,1$ & 8 & 3,8 & 26,7 \\
1979 & $12.285,4$ & 9 & 3,3 & 30,0 \\
1994 & $11.895,2$ & 10 & 3,0 & 33,3 \\
1975 & $11.863,5$ & 11 & 2,7 & 36,7 \\
1992 & $11.693,0$ & 12 & 2,5 & 40,0 \\
1990 & $11.217,0$ & 13 & 2,3 & 43,3 \\
1988 & $11.217,0$ & 13 & 2,3 & 43,3 \\
1998 & $11.146,8$ & 14 & 2,1 & 46,7 \\
1993 & $10.606,4$ & 15 & 2,0 & 50,0 \\
1996 & $10.240,1$ & 16 & 1,9 & 53,3 \\
1989 & $9.665,3$ & 17 & 1,8 & 56,7 \\
2003 & $9.177,1$ & 18 & 1,7 & 60,0 \\
1999 & $9.137,7$ & 19 & 1,6 & 63,3 \\
1977 & $9.086,7$ & 20 & 1,5 & 66,7 \\
1981 & $9.031,1$ & 21 & 1,4 & 70,0 \\
2000 & $8.559,6$ & 22 & 1,4 & 73,3 \\
1991 & $8.453,3$ & 23 & 1,3 & 76,7 \\
1980 & $8.384,5$ & 24 & 1,3 & 80,0 \\
2001 & $8.129,4$ & 25 & 1,2 & 83,3 \\
1976 & $7.929,1$ & 26 & 1,2 & 86,7 \\
1995 & $4.791,4$ & 27 & 1,1 & 90,0 \\
1978 & $3.295,0$ & 28 & 1,1 & 93,3 \\
Média & $11.217,0$ & - & - & - \\
DP & $4.163,6$ & - & - & - \\
CV(\%) & 37,1 & - & - & - \\
\hline & & & & \\
\hline
\end{tabular}

mediário e atrasado, em Quaraí, RS, que são valores menores para os padrões avançado e intermediário que os encontrados para Santa Rosa. Com a maior proporção do padrão avançado, pode-se inferir que perdas de solo na região de Santa Rosa, RS, são menores do que poderiam ser, caso houvesse predominância dos padrões intermediário ou atrasado, o que, conforme observado por Mehl et al. (2001), ocorre pelo fato de que, nas chuvas de padrão hidrológico avançado, no momento do pico de maior intensidade de chuva o solo está

Tabela 6. Padrões de chuvas naturais avançado, intermediário e atrasado em Santa Rosa, RS, no período de 1975 a 2003

\begin{tabular}{|c|c|c|c|c|c|c|}
\hline \multirow{3}{*}{$\begin{array}{l}\text { Padrão } \\
\text { Hidrológico }\end{array}$} & \multirow{2}{*}{\multicolumn{2}{|c|}{ Número de chuvas }} & \multicolumn{4}{|c|}{ Média anual } \\
\hline & & & \multicolumn{2}{|c|}{ Chuvas } & \multicolumn{2}{|c|}{ Erosividade } \\
\hline & Absoluto & $\%$ & $\begin{array}{l}\text { Total } \\
\mathrm{mm}\end{array}$ & $\%$ & $\begin{array}{c}\text { Total } \\
\text { MJ } \mathrm{mm} \mathrm{ha}^{-1} \mathrm{~h}^{-1}\end{array}$ & $\%$ \\
\hline Avançado & 664 & 52,1 & 952,4 & 57,9 & $6.924,5$ & 61,9 \\
\hline Intermediário & 306 & 24,0 & 373,3 & 22,6 & $2.453,2$ & 21,4 \\
\hline Atrasado & 304 & 23,9 & 316,1 & 19,5 & 1839,6 & 16,7 \\
\hline TOTAL & 1.274 & 100,0 & 1641,8 & 100,0 & $11.217,3$ & 100,0 \\
\hline
\end{tabular}


menos úmido que no caso dos outros padrões, por conseguinte com desagregação, selamento superficial e transporte de solo menor do que com os outros padrões, fato este comprovado por Eltz et al. (2001), que observaram maior erosão em chuvas do padrão atrasado em relação aos padrões intermediário e avançado, que não diferiram entre si, o que foi explicado pela alteração da superfície e conteúdo de água do solo no decorrer da chuva.

Carvalho et al. (2005) obtiveram valores de 61 e 58\%, respectivamente, para o número total de chuvas no padrão avançado para Seropédica e Nova Friburgo, que são maiores do que o obtido para Santa Rosa (52\%).

\section{CONCLUSÕES}

1. O valor do fator " $R$ " da Equação Universal de Perdas de Solo é de 11.217 MJ mm ha- $\mathrm{M}^{-1}$ ano $^{-1}$, caracterizando elevado potencial erosivo das chuvas.

2. O período de outubro a março é o mais crítico em relação ao potencial erosivo das chuvas, concentrando $60 \%$ da erosividade anual.

3. O padrão hidrológico avançado é o de maior ocorrência, seguido dos padrões intermediário e atrasado em relação ao número, quantidade média e erosividade média anual das chuvas erosivas.

4. O fator "R" da USLE, para regiões do entorno, com características climáticas semelhantes, pode ser estimado com dados de pluviometria usando-se a equação linear ajustada.

5. Espera-se que o valor da erosividade média anual das chuvas de 11.217 $\mathrm{MJ} \mathrm{mm} \mathrm{ha}^{-1} \mathrm{~h}^{-1}$ ano $^{-1}$, ocorra pelo menos uma vez a cada 2,3 anos, com probabilidade de ocorrência de $43,3 \%$.

\section{AGRADECIMENTOS}

Aos observadores meteorológicos da estação de Santa Rosa que, com seu trabalho contínuo, incansável e anônimo, possibilitaram a obtenção dos dados de chuva; à FEPAGRO, por ter disponibilizado os pluviogramas da estação agrometeorológica de Santa Rosa; à FAPERGS e ao CNPq, por terem disponibilizado bolsas de iniciação científica.

\section{LITERATURA CITADA}

Albuquerque, A. W.; Lombardi Neto, F.; Srinivasan, V. S.; Cantaneo, A. Parâmetros erosividade da chuva e da enxurrada correlacionados com as perdas de solo de um solo Bruno Não Cálcico de Sumé-PB. Revista Brasileira de Ciência do Solo, v.22, n.4, p.743-749, 1998.

Bertol, I. Índice de erosividade $\left(\mathrm{EI}_{30}\right)$ para Lages, SC. $1^{\mathrm{a}}$ aproximação. Pesquisa Agropecuária Brasileira, v.28, p.515-521, 1993.

Carvalho, D. F. de; Montebeller, C. A.; Franco, E. M. Valcarcel, R.; Bertol, I. Padrões de precipitação e índices de erosividade para as chuvas de Seropédica e Nova Friburgo, RJ. Revista Brasileira de Engenharia Agrícola e Ambiental, v.9, n.1, p.7-14, 2005.
Carvalho, M. de P. E.; Lombardi Neto, F.; Vasques Filho, J.; Catâneo, A. Correlação entre o índice de erosividade $\mathrm{EI}_{30}$ médio mensal e o coeficiente de chuva do município de Mococa, SP. Científica - Revista de Agronomia, v.19, p.17, 1991.

Cogo, C. M.; Eltz, F. L. F.; Cassol, E. A. Erosividade das chuvas em Santa Maria, determinada pelo índice $\mathrm{EI}_{30}$. Revista Brasileira de Agrometeorologia, v.14, p.1-11, 2006.

Colodro, G.; Carvalho, M. P.; Roque, C. G.; Prado, R. M. Erosividade da chuva: distribuição e correlação com a precipitação pluviométrica de Teodoro Sampaio (SP). Revista Brasileira de Ciência do Solo, v.26, p.809-818, 2002.

Eltz, F. L. F.; Mehl, H. U.; Reichert, J. M. Perdas de solo e água em entressulcos em um Argissolo Vermelho-Amarelo submetido a quatro padrões de chuva. Revista Brasileira de Ciência do Solo, v.25, p.485-493, 2001.

Foster, G. R.; McCool, D. K.; Renard, K. G.; Moldenhauer, W. C. Conversion of the universal soil loss equation to SI units. Journal of Soil and Water Conservation, v.36, p.355-359, 1981.

Horner, W. W.; Jens, S. W. Surface runoff determination from rainfall without using coefficients. Transactions of the ASCE, v.107, p.1039-1117, 1942.

Lombardi Neto, F. Rainfall erosivity - its distribution and relationship with soil loss at Campinas, Brazil. West Lafayette: Purdue University, 1977. 53p. Dissertação Mestrado

Marques, J. J. G. de S. e M.; Alvarenga, R. C.; Curi, N. Erosividade das chuvas da região de Sete Lagoas, MG. Pesquisa Agropecuária Brasileira, v.33, n.5, p.761-768, 1998.

Marques, J. J. G. de S. e M.; Alvarenga, R. C.; Curi, N.; Santana, D. P.; Silva, M. L. N. Índices de erosividade da chuva, perdas de solo e fator erodibilidade para dois solos da região dos cerrados - primeira aproximação. Revista Brasileira de Ciência do Solo, v.21, p.427-434, 1997.

Mehl, H. U.; Eltz, F. L. F.; Reichert, J. M.; Didoné, I. A. Caracterização dos padrões de chuva ocorrentes em Santa Maria, RS. Revista Brasileira de Ciência do Solo, v.25, p.475-483, 2001.

Morais, L. F. B. de; Mutti, L. S. M.; Eltz, F. L. F. Índices de erosividade correlacionados com perdas de solo no Rio Grande do Sul. Revista Brasileira de Ciência do Solo, v.25, p.485-493, 1988.

Morais, L. F. B. de; Silva, V. da; Naschenveng, T. M. da C.; Hardoin, P. C; Almeida, J. E. L. de; Weber, O. L. dos S.; Boel, E.; Durigon, E. Índice $\mathrm{EI}_{30}$ e sua relação com o coeficiente de chuva do sudoeste do Mato Grosso. Revista Brasileira de Ciência do Solo, v.15, p.339-344, 1991.

Moreti, D.; Carvalho, M. P.; Mannigel, A. R.; Medeiros, L. $\mathrm{R}$. Importantes características de chuva para a conservação do solo e da água no município de São Manuel, SP. Revista Brasileira de Ciência do Solo, v.27, p.713-725, 2003.

Peñalva-Bazzano, M. G.; Eltz, F. L. F.; Cassol, E. A. Erosividade, coeficiente de chuva, padrões e período de retorno das chuvas de Quaraí, RS. Revista Brasileira de Ciência do Solo, v.31, p.1205-1217, 2007. 
Rio Grande do Sul. Secretaria da Agricultura e Abastecimento. Centro Nacional de Pesquisa de Trigo. Macrozoneamento agroecológico e econômico do Estado do Rio Grande do Sul. Porto Alegre: Secretaria de Agricultura e Abastecimento, 1994. 2v. 307p.

Roque, C. G.; Carvalho, M. P.; Prado, R. M. Fator erosividade da chuva de Piraju (SP): Distribuição, probabilidade de ocorrência, período de retorno e correlação com o coeficiente de chuva. Revista Brasileira de Ciência do Solo, v.25, p.147-156, 2001.

Rufino, R.; Biscaia, R. C. M.; Merten, G. H. Avaliação do potencial erosivo da chuva do estado do Paraná, através de pluviometria: terceira aproximação. Revista Brasileira de Ciência do Solo, v.17, p.439-444, 1993.
Schwab, G. O.; Frevert, R. K.; Edminster, T. W.; Barnes, K. K. Soil and water conservation engineering. 3.ed. New York: John Wiley \& Sons, 1981. 525p.

Wischmeier, W. H. A rainfall erosion index for a universal soilloss equation. Soil Science Society of America Proceedings, v.23, p.246-249, 1959.

Wischmeier, W. H. Use and misuse of the universal soil loss equation. Journal of Soil and Water Conservation, v.31, p.59, 1976.

Wischmeier, W. H.; Smith, D. D. Predicting rainfall erosion losses - A guide to conservation planning. Washington: USDA. 58p. 1978. Agriculture Handbook 537 